\title{
Sexual behaviour and risk of sexually transmitted infections in young female healthcare students in Spain.
}

Felipe Navarro-Cremades, Antonio Palazón-Bru, Dolores Marhuenda-Amorós, María I Tomás-Rodríguez, Fina Antón-Ruiz, Josefina Belda-Ibañez, Ángel L Montejo, Vicente F Gil-Guillén

Background: Several authors have examined the risk for sexually transmitted infections (STI), but no study has yet analyzed it solely in relation with sexual behaviour in women.

We analyzed the association of sexual behaviour with STI risk in female university students of healthcare sciences. Methods: We designed a cross-sectional study assessing over three months vaginal intercourse with a man. The study involved 175 female university students, without a stable partner, studying healthcare sciences in Spain. Main outcome variable: STI risk (not always using male condoms). Secondary variables: sexual behaviour, method of orgasm, desire to increase the frequency of sexual relations, desire to have more variety in sexual relations, frequency of sexual intercourse with the partner, and age. The information was collected with an original questionnaire. A logistic regression model was used to estimate the adjusted odds ratios (ORs) in order to analyze the association between the STI risk and the study variables. Results: Of the 175 women, 52 were positive for STI risk (29.7\%, 95\% Cl: 22.9-36.5\%). Factors significantly associated with STI risk $(p<0.05)$ included: orgasm (not having orgasms $\rightarrow O R=7.01,95 \% \mathrm{Cl}: 1.49-33.00$; several methods $\rightarrow O R=0.77,95 \% \mathrm{Cl}: 0.31-1.90$; one single method $\rightarrow O R=1 ; p=0.008$ ) and desiring an increased frequency of sexual activities $(\mathrm{OR}=0.27,95 \% \mathrm{Cl}: 0.13-0.59, \mathrm{p}<0.001)$. Conclusions: Women's desire for sexual activities and their sexual function were significant predictors of their risk for STI. Information about sexual function is an intrinsic aspect of sexual behaviour and should be taken into consideration when seeking approaches to reduce risks for STI. 


\section{AUTHOR COVER PAGE:}

2 Title: Sexual behaviour and risk of sexually transmitted infections in young female healthcare

3 students in Spain.

4 Authors:

5 Felipe Navarro-Cremades ${ }^{1}$, Antonio Palazón-Bru ${ }^{1}$, Dolores Marhuenda-Amorós ${ }^{2}$, María Isabel

6 Tomás-Rodríguez ${ }^{2}$, Fina Antón-Ruiz ${ }^{3}$, Josefina Belda-Ibañez ${ }^{4}$, Ángel Luis Montejo ${ }^{5}$, Vicente

7 Francisco Gil-Guillén'1.

8 1. Department of Clinical Medicine, Miguel Hernández University, San Juan de Alicante,

9 Alicante, Spain.

10 2. Department of Pathology and Surgery, Miguel Hernández University, San Juan de Alicante, 11 Alicante, Spain.

12 3. Department of Education, San Antonio Catholic University, Murcia, Murcia, Spain.

13 4. Centre for Information and AIDS Prevention, Conselleria de Sanitat, Alicante, Alicante, 14 Spain.

15 5. Department of Psychiatry, University of Salamanca, Salamanca, Salamanca, Spain.

17 Corresponding author: Prof. A. Palazón-Bru, PhD. Department of Clinical Medicine, Miguel

18 Hernández University, Carretera de Valencia - Alicante S/N 03550 San Juan de Alicante.

19 Telephone: +34 965919449. Fax: +34 965919450. E-mail: antonio.pb23@gmail.com 


\section{ABSTRACT}

22 Background: Several authors have examined the risk for sexually transmitted infections (STI),

23 but no study has yet analyzed it solely in relation with sexual behaviour in women. We analyzed

24 the association of sexual behaviour with STI risk in female university students of healthcare

25 sciences.

26 Methods: We designed a cross-sectional study assessing over three months vaginal intercourse

27 with a man. The study involved 175 female university students, without a stable partner,

28 studying healthcare sciences in Spain. Main outcome variable: STI risk (not always using male

29 condoms). Secondary variables: sexual behaviour, method of orgasm, desire to increase the

30 frequency of sexual relations, desire to have more variety in sexual relations, frequency of sexual

31 intercourse with the partner, and age. The information was collected with an original

32 questionnaire. A logistic regression model was used to estimate the adjusted odds ratios (ORs) in

33 order to analyze the association between the STI risk and the study variables.

34 Results: Of the 175 women, 52 were positive for STI risk (29.7\%, 95\% CI: 22.9-36.5\%). Factors

35 significantly associated with STI risk $(\mathrm{p}<0.05)$ included: orgasm (not having

36 orgasms $\rightarrow \mathrm{OR}=7.01,95 \% \mathrm{CI}: 1.49-33.00$; several methods $\rightarrow \mathrm{OR}=0.77,95 \% \mathrm{CI}: 0.31-1.90$; one

37 single method $\rightarrow \mathrm{OR}=1 ; \mathrm{p}=0.008$ ) and desiring an increased frequency of sexual activities

$38(\mathrm{OR}=0.27,95 \% \mathrm{CI}: 0.13-0.59, \mathrm{p}<0.001)$.

39 Conclusions: Women's desire for sexual activities and their sexual function were significant

40 predictors of their risk for STI. Information about sexual function is an intrinsic aspect of sexual

41 behaviour and should be taken into consideration when seeking approaches to reduce risks for

42 STI. 


\section{INTRODUCTION}

44 Sexually transmitted infections (STI) are spread primarily through person-to-person sexual

45 contact. There are more than 30 different sexually transmissible bacteria, viruses and parasites

46 (World Health Organization, 2015). The most common conditions caused are gonorrhea,

47 chlamydial infection, syphilis, trichomoniasis, chancroid, genital herpes, genital warts, human

48 immunodeficiency virus (HIV) infection and hepatitis B infection (World Health Organization,

49 2015). The latex condom for males is the single most efficient available technology to reduce the

50 sexual transmission of HIV and other STI as well as offering protection for the prevention of

51 unintended pregnancy (Holmes, Levine \& Weaver, 2004). For example, the risk of a woman

52 contracting HIV per unprotected sexual act with an infected man is $0.1 \%$ (twenty times less per

53 protected sexual act) (Varghese et al., 2002).

In Spain, about one in every seven women under the age of 30 years has had sexual

55 intercourse with a casual partner during the previous year (Instituto Nacional de Estadística,

56 2004). Moreover, as only three in five always use a condom with casual partners, an important

57 percentage of these women are at risk of contracting a STI (Instituto Nacional de Estadística,

58 2004). The percentage of women who are married is very similar in Spain to the rest of Europe,

59 as well as to the US, though it is difficult to compare with rates in Africa as these data are not

60 always recorded (Orten, 2008; Instituto Nacional de Estadística, 2011; Herbenick et al., 2013).

61 STI, however, are more common in developed countries (Spain, US, etc.), followed by south and

62 southeast Asia and sub-Saharan Africa (Gewirtzman et al., 2011). The most prevalent STI in

63 women are trichomoniasis (Spain and Africa), HPV (US) and chlamydia (Europe) (World Health

64 Organization, 2001; Instituto Nacional de Estadística, 2004; Johnson, Coetzee \& Dorrington,

65 2005; Gewirtzman et al., 2008; European Centre for Disease Prevention and Control, 2010; 
66 Satterwhite et al., 2013). Spanish women, though, are less unfaithful than others in Europe, or in

67 Africa and the US (Conley et al., 2012; The Institut français d'opinion publique, 2014; Onoya et

68 al., 2015). In Spain, as everywhere, religion is a factor that influences the use of condoms

69 (Cooksey, Rindfuss \& Guilkey, 1996; Instituto Nacional de Estadística, 1999; Lazarus et al., 70 2009; De Neve, 2013).

71 Scholars have examined risky sexual behaviour in different populations but none have

72 focused specifically on sexual behaviour and sexual function in women (Table 1). Studies have

73 been done, though, on the association between sexual behaviour and infection with a particular

74 STI (not the risk of contracting the infection), such as bacterial vaginosis (Nilsson et al., 1997),

75 or the association between the use of a condom at sexual debut and the STI risk in American

76 adolescents (Shafii, Stovel \& Holmes, 2007). To fill this gap in the literature, we designed a

77 study involving university women studying for a healthcare qualification. Questionnaires

78 assessed the lack of use of the male condom during sexual activities with casual partners and its

79 association with various different types of sexual function/behaviour. The results of the study

80 suggest the need for future educational measures to prevent STI in healthcare personnel.

81

82 MATERIALS \& METHODS

83 Study population

84 The study involved women studying for a healthcare qualification at Miguel Hernández

85 University (Medicine, Pharmacy, Physiotherapy, Podiatry, and Occupational Therapy) in San

86 Juan de Alicante (Spain). These degrees are studied by $28.3 \%$ of Spanish women who attend

87 universities (Instituto Nacional de Estadística, 2005). The main characteristics of this population

88 are: age 18-25 years, middle to high socio-economic status, single status (in Spain the average 
89 age at first marriage is 31.68 years) (Instituto Nacional de Estadística, 2012), and interested in

90 health sciences. Regarding sexual orientation, $2.7 \%$ of women report having had a homosexual

91 relationship during their lifetime (Instituto Nacional de Estadística, 2004).

92 Study design and participants

93 This cross-sectional observational study, undertaken between February 2005 and February 2009,

94 selected a sample of university students studying healthcare sciences at Miguel Hernández

95 University, Elche. The sample comprised all female third-year students studying medicine and

96 second-year female students studying occupational therapy who attended lectures on a particular

97 day during the study period and who wished to participate voluntarily. Data from women who

98 did not wish to participate were not used for the analysis. The data were collected in classrooms

99 with space for 100 to 200 students, but which are not generally full. In addition, all the

100 participants had to have had vaginal intercourse with a man during the three months prior to

101 completing the questionnaire and not have a stable partner; i.e., have had at least one sexual

102 encounter with someone she did not identify as a stable partner and this partner was open to

103 sexual activities with others. This information was assessed by specific questions, shown in the

104 Appendix of a previous paper (Navarro-Cremades et al., 2015).

105 Variables and measurements

106 The information was collected with an original questionnaire [See Appendix of the previous

107 paper (Navarro-Cremades et al., 2015)]. Prior to distributing the questionnaire a verbal

108 introduction was given explaining the voluntary and anonymous nature of the survey, as well as

109 the confidentiality of all the data. The participants were requested to be sincere in their

110 responses. The same researcher always provided the prior standard information, handed out the

111 questionnaires, was present during their completion, and addressed any questions. The 
112 questionnaire took approximately 25 minutes to complete. The validity of the questionnaire was

113 assessed during a prior pilot study that used 114 female third-year medicine undergraduates in

114 May 2004. The results of this pilot study showed the good psychometric characteristics of the

115 questionnaire (analysis of items and internal consistency, indexes of discrimination and factorial 116 analysis) (Van-der Hofstadt et al., 2007-2008; Navarro-Cremades et al., 2013).

117 The questionnaire used in this study collected information about various female

118 sexological aspects (Van-der Hofstadt et al., 2007-2008; Navarro-Cremades et al., 2013;

119 Navarro-Cremades et al., 2015). This study only used those items considered most relevant by

120 the research team. The main outcome variable was the risk of a STI. This was defined as not

121 having used a male condom in at least one of their vaginal sexual relations with casual male

122 partners. To assess this, questions were asked about contraception methods used (condoms, oral

123 contraceptives, none, withdrawal, intrauterine device, vaginal ring, patch, several methods, or

124 abstinence) (Navarro-Cremades et al., 2015). If a woman failed to use a condom in any act

125 involving intercourse, she was considered to be positive for STI risk, as regardless of whether

126 she used a condom in other sexual encounters or with other partners, she had a risk behaviour at

127 least once, and could therefore have been infected. On the other hand, this study did not assess

128 sexual relations with other males in women who had a stable partner.

129 The secondary variables analyzed included: sexual orientation (heterosexual, bisexual or

130 other), how do you normally achieve orgasm? (no orgasm, several methods, or a single method)

131 (in the questionnaire the possible answers were: during vaginal intercourse, through fantasies and

132 daydreams, by stimulation from my partner, by self stimulation, through various of the previous

133 methods, I don't have orgasms, by other methods. As the responses varied greatly, we formed

134 the following groups: one method, several methods, none of the methods), desire to increase the 
135 frequency of sexual activities (yes and no), desire to have more variety in sexual activities (hour

136 of the day, position, etc.) (yes and no), frequency of sexual intercourse with the partner (6 $\rightarrow 5-7$

137 times/week; $5 \rightarrow 3-4$ times/week; $4 \rightarrow 1-2$ times/week; $3 \rightarrow 2-3$ times/month; $2 \rightarrow$ once/month),

138 and age (in years) (Navarro-Cremades et al., 2015).

139 Sample size

140 The overall sample size comprised the 175 university students who completed the questionnaire.

141 All had had vaginal intercourse with a man during the three months prior to completing the

142 questionnaire and did not have a stable partner. To determine which women fulfilled these

143 characteristics we analyzed all the questionnaires completed $(n=565)$ and assessed the questions

144 Sexual orientation, are you in a stable relationship? and Method of contraception that you use

145 (Navarro-Cremades et al., 2015). Thus, using a significance of 5\% and an expected proportion of

$14638.1 \%$ (proportion of women $<30$ years of age in Spain who do not always use a male condom

147 with casual partners), the expected error in the estimation of the STI risk was 7.2\% (Instituto

148 Nacional de Estadística, 2004).

149 Statistical analysis

150 As the study involved data from different years, we first checked that there were no variations

151 over time in any of the variables measured, using the Chi square test of Pearson or Fisher

152 (qualitative data), and ANOVA or Kruskal-Wallis (quantitative data). In the event of a difference

153 over time being found, time would then be added as an explanatory variable in all the statistical

154 tests done; otherwise time would not be included in any analysis. After checking this possibility,

155 absolute and relative frequencies were used to describe the qualitative variables and means plus

156 standard deviations for the quantitative variables. A multivariate logistic regression model was

157 used to estimate the adjusted odds ratios (ORs) in order to analyze the association between the 
158 STI risk and the study variables. As we had 52 events in our sample (women with a STI risk), we

159 could only introduce 5 explanatory variables in the model (one for every 10 events). To select

160 these variables, we constructed a stepwise model based on the likelihood ratio test. Using this

161 method, we obtained the adjusted ORs for the selected combination of explanatory variables.

162 The prognostic likelihood of the STI risk in the multivariate model was transformed into charts

163 to help interpret the results. The likelihood ratio test and the Hosmer-Lemeshow test were carried

164 out for the goodness-of-fit of the model. Furthermore, we represented the ROC curve for the

165 predicted probabilities of STI risk given by the model. All analyses were performed at a 5\%

166 significance level and associated confidence intervals (CI) were estimated for each relevant

167 parameter. All the analyses were performed using SPSS 19.

168 Ethical considerations

169 This study was approved by the Ethics Commission of Miguel Hernández University, Elche

170 (reference DMC.FNC.01.14). All the study participants agreed verbally to collaborate

171 voluntarily, anonymously and freely, with no direct reward for their participation or penalization

172 for non participation. Any woman who did not wish to participate could leave the classroom

173 before the questionnaires were handed out. To ensure confidentiality no personal data were

174 recorded that could lead to identification of the participants.

175

176 RESULTS

177 A total of 601 female students attended class on the day in question, of whom nine declined the

178 invitation to participate. Another 15 had not had any sexual activity during the previous three

179 months and did not, therefore, complete the questionnaire. Seven students did not hand in the

180 questionnaire and five handed it in without filling it in, leaving a total of 565 completed 
181 questionnaires. Of these, 370 women were excluded because they either had a stable partner or

182 because they had not indicated on the questionnaire the method of contraception used. On the

183 other hand, 20 women were excluded because some of the selected variables for this study had

184 missing values. Thus, the final sample comprised 175 women.

185

As no variable varied over time ( $\mathrm{p}>0.05)$, time was not used as an explanatory variable in

186

any analysis. Table 2 summarizes the information concerning the analysis of the STI risk

187 ( $\mathrm{n}=175)$. Most of the women who participated in the study were heterosexual (96.0\%) and

188 achieved orgasm through different methods (74.9\%). Half were satisfied with the frequency of

189 their sexual relations (52.6\%) and one third desired more variety in their sex lives (34.3\%). The

190 mean age was almost 21 years (20.8), as the sample comprised university students.

191 The main contraceptive methods used were: male condom, 123 (70.3\%); oral

192 contraceptives, 14 (8.0\%); contraceptive patches, 1 (0.6\%); various, 8 (4.6\%); none, 29 (19.0\%).

193 Thus, 52 of the 195 women surveyed did not always use a male condom (STI risk) (29.7\%, 95\%

194 CI: 22.9-36.5\%).

195

The factors significantly associated with the risk of STI $(\mathrm{p}<0.05 / \mathrm{p}<0.025$ for the multiple

196

comparison in Method of orgasms $\rightarrow$ Bonferroni correction) were: not having orgasms and not

197 desiring an increased frequency of sexual relations. The model was significant and the Hosmer-

198 Lemeshow test did not show discrepancies between expected and observed events. The area

199 under the ROC curve was high (Fig. 1).

200 Figure 2 shows a box chart with the following elements: method of orgasm on the $\mathrm{x}$-axis,

201 with the y-axis showing the prognostic likelihood of the STI risk obtained from the multivariate

202 logistic regression model. Figure 2 also shows that those women with no orgasm had a greater

203 likelihood of a STI risk. The same process with the x-axis showing the desire for an increased 
204 frequency of sexual relations (Fig. 3) gave a greater likelihood of STI risk in the women who did 205 not wish to increase the frequency of their sexual relations.

206

207 DISCUSSION

208 In this study we found that one in every three women was at risk of contracting a STI by not

209 using a male condom in all their casual vaginal sexual relations with men. A literature search of

210 studies analyzing this problem found that it varied between $20 \%$ and $69 \%$. The proportion of

211 those at risk for a STI in our study was near the lower limit, indicating that this behaviour is less

212 usual than in other populations. This may be because our participants were more aware of STI

213 than the participants in other studies (Table 1).

214 Concerning the factors associated with the STI risk, the authors of these other studies

215 found that no casual sex expectations, no alcohol consumption, being cautious regarding casual

216 sex, embarrassed to discuss condoms, living in urban areas, with a middle to highest wealth

217 index, and taking oral contraceptive pills were associated with a STI risk. On the other hand,

218 there were discrepancies regarding educational attainment (Table 1). Regarding the

219 socioeconomic factors, our sample was taken from a population living in urban areas and with a

220 high educational level. Maybe this could produce a higher prevalence of STI risk than the studies

221 which found these factors associated with STI risk (Paasche-Orlow et al., 2005; Berhan \&

222 Berhan, 2012). In our study we only examined factors related with sexual behaviour, and cannot

223 therefore compare the results obtained. Firstly, we found that those women who did not achieve

224 orgasm had a greater STI risk. This behaviour may be due to the fact that these women attempt

225 to achieve orgasms by not using a condom in order to experience greater contact during sexual

226 intercourse. Although this factor has been found to have an inverse association with infection by 
227 bacterial vaginosis, it is not comparable with the results of our study as, firstly the population of

228 the other study was obtained from family planning clinics and secondly, we assessed the risk of

229 contracting a STI whereas the other study determined the prevalence of the infection itself

230 (Nilsson et al., 1997). Secondly, our results indicate that the women who were satisfied with the

231 frequency of their sexual relations had a greater STI risk. This may be because persons who

232 desire a greater sexual frequency acquire a more prudent behaviour regarding STI. Finally,

233 although not quite reaching statistical significance, we found that less desire for greater sexual

234 variety was also associated with this risk behaviour. As with the previous case, this may be due

235 to the fact that persons who wish to increase their sexual variety are more aware of the risk, and

236 therefore attempt to minimize the risk by greater use of a condom.

237 When we started this study we expected to find a lower magnitude of STI risk. However,

238 the magnitude was unexpected, as one in every three women training to become a healthcare

239 professional within a few years had a risk behaviour of contracting a STI. This is worrying, as in

240 this population knowledge about STI and their prevention is higher than in the general

241 population and yet STI risk behaviour was nevertheless very prevalent.

242 The fact that we found that not having orgasms was associated with the lack of condom

243 use in this type of relations raises an important point often neglected in educational programs

244 about STI prevention, as these women are putting their sexual pleasure before STI prevention.

245 These results are important, considering that it is these very persons who should, in the future,

246 make the population aware of the severity of this problem.

247 Healthcare personnel should be actively involved in the fight against STI by means of

248 educational programs in the general population (Fageeh, 2014). Our results suggest that future

249 members of this profession are not fully aware of the severity of the problem. Accordingly, the 
250 university curriculum should include specific programs about STI prevention and not rely solely

251 on education, since it is clear that simply knowing that condoms are necessary to protect from

252 STI infection is not nearly enough to modify behaviour. The hope is that, when these students

253 eventually become qualified healthcare personnel they can, in turn, raise awareness and promote

254 motivation for protective and preventative methods amongst the general population. Another

255 solution to this problem could be the condom use initiative and public awareness campaign,

256 because other authors have shown that if the couple has used the condom in the past, the

257 likelihood of using it in the future increases (Shafii, Stovel \& Holmes, 2007). In other words, we

258 could reduce the prevalence of the STI risk.

259 Strengths and limitations of the study

260 The main strength of this study concerns the lack of studies analyzing the magnitude of this

261 problem and its association with the sexual behaviour of women studying healthcare sciences.

262 Thus, our results are innovative and indicate that sexual practices among these particular female

263 university students are associated with the risk of contracting a STI.

264 The limitations are defined by its design. As this was a cross-sectional study we are

265 unable to establish any temporality between the factors analyzed and the STI risk. This would

266 require future longitudinal studies involving predictive models to determine which women are

267 more likely to develop this particular behaviour and undertake an early intervention with

268 educational activities to avoid the problem (STI risk). In order to minimize the information bias,

269 the source corresponded to an instrument with good psychometric properties that reliably

270 indicated the answers given by the participants (Van-der Hofstadt et al., 2007-2008; Navarro-

271 Cremades et al., 2013). No measurements were made of factors that could influence the risk of

272 STI, such as the attitude of the male partner, desire, arousal, lubrication, satisfaction, pain, sexual 
273 abuse, group sex practice, drugs and alcohol consumption, or the number of partners during the

274 study period, though we did analyze the frequency of coital sexual activity during the study

275 period. In addition, the AUC of the model was 0.75 , so that the combination of our factors can

276 explain the outcome satisfactorily. Also, the main outcome variable was the risk of STI and this

277 was defined solely as not having used a male condom in at least one of their vaginal sexual

278 relations with a casual male partner. To assess the real STI risk we have to take into account

279 other aspects of the sexual encounters. This would increase the prevalence of STI risk. This issue

280 will be considered in future studies. Finally, to minimize the selection bias, participants were

281 selected once they had studied all the aspects of a STI. Thus, the students were aware of the lack

282 of prevention and its consequences. We have to take into account that the objective of our study

283 was to quantify the prevalence of STI in future health care personnel, not in the general

284 population, because we have to take measures at this stage to try to prevent STI in the general

285 population, as discussed throughout the manuscript.

286

287 CONCLUSIONS

288 Taking into account that these women had studied STI and their prevention, the mere knowledge

289 did not appear to be enough to motivate behavioural changes. The fact that not having an orgasm

290 was a risk factor for not using a condom suggests that people make decisions about condom use

291 based on reinforcers such as pleasure rather than as the result of logical and analytical evaluation

292 of the long-term pros and cons; therefore, our program should not just focus on education and

293 providing knowledge, it needs to move towards increasing motivation to change (Pollack, Boyer

294 \& Weinstein, 2013). However, our results should be taken with caution because we have not 
295 analyzed other relevant factors for STI risk or determined the test - retest reliability (stability of 296 responses over time). These issues will be studied in future research.

297

298 ACKNOWLEDGMENTS

299 We thank the Department of Applied Psychology of Miguel Hernández University, Elche, for 300 allowing us to use the questionnaire for this study, and Felipe Navarro Sánchez for helping with 301 the computerization of the data base. The authors also thank Ian Johnstone for help with the 302 English language version of the text. Finally, the authors thank Alessandra Rellini for her helpful 303 comments.

304 


\section{REFERENCES}

306 Apostolopoulos Y, Sönmez S, Yu CH. 2002. HIV-risk behaviours of American spring break 307 vacationers: a case of situational disinhibition? International Journal of STD \& AIDS 13: 733308743.

309

310 Berhan A, Berhan Y. 2012. A Meta-Analysis on Higher-Risk Sexual Behavior of Women in 28 311 Third World Countries. World Journal of AIDS 2:78-88.

312

313 Conley TD, Moors AC, Ziegler A, Karathanasis C. 2012. Unfaithful individuals are less likely to 314 practice safer sex than openly nonmonogamous individuals. The Journal of Sexual Medicine 9: 315 1559-1565.

316

317 Cooksey EC, Rindfuss RR, Guilkey DK. 1996. The initiation of adolescent sexual and 318 contraceptive behaviour during changing times. Journal of Health and Social Behavior 37: 5931974.

320

321 De Neve JW. 2013. 'Pope as prevention'? Condom use by Catholics increased in five HIV 322 endemic countries in sub-Saharan Africa during Pope Benedict XVI's tenure.

323 AIDS 27: 2829-2830. 2014 Erratum in: AIDS 28: 145-146.

324

325 de Visser RO, Smith AM, Rissel CE, Richters J, Grulich AE. 2003. Sex in Australia: safer sex 326 and condom use among a representative sample of adults. Australian and New Zealand Journal 327 of Public Health 27: 223-229. 
329 European Centre for Disease Prevention and Control. 2010. Annual Epidemiological Report on 330 Communicable Diseases in Europe 2010. Stockholm: ECDC.

331

332

333 Fageeh WM. 2014. Sexual behavior and knowledge of human immunodeficiency virus/aids and 334 sexually transmitted infections among women inmates of Briman Prison, Jeddah, Saudi Arabia. 335 BMC Infectious Diseases 14:290.

336

337 Finney H. 2003. Contraceptive use by medical students whilst on holiday. Family Practice 20: 33893.

339

340 Gewirtzman A, Bobrick L, Conner K, Tyring SK. 2011. Epidemiology of Sexually Transmitted 341 Infections. In: Gross GE, Tyring SK, eds. Sexually Transmitted Infections and Sexually

342 Transmitted Diseases. Berlin Heidelberg: Springer Verlag.

343

344 Herbenick D, Schick V, Reece M, Sanders SA, Smith N, Dodge B, Fortenberry JD. 2013.

345 Characteristics of condom and lubricant use among a nationally representative probability 346 sample of adults ages 18-59 in the United States. The Journal of Sexual Medicine 10: 474-483. 347

348 Herlitz C. 2009. Sexual risk-taking in the general population of Sweden (1989-2007). Sexual 349 Health 6: 272-280. 
351 Holmes KK, Levine R, Weaver M. 2004. Effectiveness of condoms in preventing sexually

352 transmitted infections. Bulletin of the World Health Organization 82: 454-461.

353

354 Instituto Nacional de Estadística. 1999. Encuesta de fecundidad. Available at

355 http://ine.es/jaxi/menu.do? type $=$ pcaxis\&path $=/ t 20 / p 317 \&$ file $=$ inebase $\& L=0$ (accessed

356 September 2015).

357

358 Instituto Nacional de Estadística. 2004. Salud y hábitos sexuales: Las conductas sexuales desde

359 la perspectiva del sida. Available at http://www.ine.es/revistas/cifraine/cifine sida0704.pdf

360 (accessed September 2015).

361

362 Instituto Nacional de Estadística. 2005. Educación Universitaria 2005. Available at:

363 http://www.ine.es/revistas/cifraine/0405.pdf Accessed July 2014 (accessed September 2015).

364

365 Instituto Nacional de Estadística. 2011. Censos de Población y Viviendas 2011. Resultados

366 definitivos. Available at http://www.ine.es/censos2011 datos/cen11_datos inicio.htm (accessed

367 September 2015)

368

369 Instituto Nacional de Estadística. 2012. Indicadores de Primo-Nupcialidad. Resultados

370 nacionales. Available at http://www.ine.es/jaxiT3/Tabla.htm?t=1380 (accessed September 2015)

371

372 Johnson LF, Coetzee DJ, Dorrington RE. 2005. Sentinel surveillance of sexually transmitted

373 infections in South Africa: a review. Sexually Transmitted Infections 81: 287-293. Review. 
375 Kiene SM, Tennen H, Armeli S. 2008. Today I'll use a condom, but who knows about tomorrow: 376 a daily process study of variability in predictors of condom use. Health Psychology 27: 463-472.

377

378

379

380

381

382

383

384

385

386

387

388

389

390

391

392

393

394

395

396

Lazarus JV, Moghaddassi M, Godeau E, Ross J, Vignes C, Ostergren PO, Liljestrand J. 2009. A multilevel analysis of condom use among adolescents in the European Union. Public Health 123: 138-144.

Navarro-Cremades F, Hernández Serrano R, Tirado González S, Rodríguez-Marín J, Van-der Hofstadt CJ, Vinci P, Llisterri-Caro JL, Llinas-Santacreu G. 2013. Propiedades psicométricas del Cuestionario sobre Sexualidad Femenina CPA. In: García Rojas AD, Cabello Santamaría F, eds. Actualizaciones en sexología clínica y educativa. Huelva: Universidad de Huelva Publicaciones.

Navarro-Cremades F, Palazón-Bru A, Arroyo-Sebastián Mdel Á, Gómez-Pérez L, Sepehri A, Martínez-Pérez S, Marhuenda-Amorós D, Rizo-Baeza MM, Gil-Guillén VF. 2015. Fear of becoming pregnant among female healthcare students in Spain. PeerJ 3: e1200.

Nilsson U, Hellberg D, Shoubnikova M, Nilsson S, Mårdh PA. 1997. Sexual behavior risk factors associated with bacterial vaginosis and Chlamydia trachomatis infection. Sexually Transmitted Diseases 24:241-246.

Onoya D, Zuma K, Zungu N, Shisana O, Mehlomakhulu V. 2015. Determinants of multiple sexual partnerships in South Africa. Journal of Public Health 37: 97-106. 
398 Orten H. 2008. Measuring legal marital status in Europe and in the European social survey.

Available at http://ec.europa.eu/eurostat/documents/1001617/4436612/1-2-H-ORTEN-REV2-

$400 \quad$ OF-15-FEB-1.pdf (accessed 7 April 2015).

401

402 Paasche-Orlow MK, Clarke JG, Hebert MR, Ray MK, Stein MD. 2005. Educational attainment

403 but not literacy is associated with HIV risk behavior among incarcerated women. Journal of

404 Women's Health (2002) 14:852-859.

405

406

Pollack LM, Boyer CB, Weinstein ND. 2013. Perceived risk for sexually transmitted infections

407 aligns with sexual risk behavior with the exception of condom nonuse: data from a nonclinical

408 sample of sexually active young adult women. Sexually Transmitted Diseases 40:388-394.

409

410 Ragsdale K, Difranceisco W, Pinkerton SD. 2006. Where the boys are: sexual expectations and

411 behaviour among young women on holiday. Culture, Health \& Sexuality 8: 85-98.

412

413 Reece M, Herbenick D, Schick V, Sanders SA, Dodge B, Fortenberry JD. 2010. Condom use

414 rates in a national probability sample of males and females ages 14 to 94 in the United States.

415 The Journal of Sexual Medicine 7 Suppl 5: 266-276.

416

417 Satterwhite CL, Torrone E, Meites E, Dunne EF, Mahajan R, Ocfemia MC, Su J, Xu F,

418 Weinstock H. 2013. Sexually transmitted infections among US women and men: prevalence and

419 incidence estimates, 2008. Sexually Transmitted Diseases 40: 187-193. 
420

421 Shafii T, Stovel K, Holmes K. 2007. Association between condom use at sexual debut and 422 subsequent sexual trajectories: a longitudinal study using biomarkers. American Journal of 423 Public Health 97:1090-1095.

424

425 The Institut français d'opinion publique. 2014. Available at

426 http://www.ifop.com/?option=com publication\&type=poll\&id=2471 (accessed October 2014).

427

428

van-der Hofstadt CJ, Antón-Ruiz FA, Tirado S, Navarro-Cremades F. 2007-2008. Hábitos

429 sexuales en mujeres estudiantes de medicina. Cuadernos de Medicina Psicosomática 84-85: 32-

430 48.

431

432 Vandepitte J, Bukenya J, Weiss HA, Nakubulwa S, Francis SC, Hughes P, Hayes R, Grosskurth 433 H. 2011. HIV and other sexually transmitted infections in a cohort of women involved in high434 risk sexual behavior in Kampala, Uganda. Sexually Transmitted Diseases 38:316-323.

435

436 Varghese B, Maher JE, Peterman TA, Branson BM, Steketee RW. 2002. Reducing the risk of 437 sexual HIV transmission: quantifying the per-act risk for HIV on the basis of choice of partner, 438 sex act, and condom use. Sexually Transmitted Diseases 29:38-43.

439

440 World Health Organization. 2001. Global prevalence and incidence of selected curable sexually 441 transmitted infections overview and estimates. Geneva: WHO. 
443 World Health Organization. 2015. Sexually transmitted infections. Available at

444 http://www.who.int/topics/sexually transmitted infections/en/ (accessed September 2015).

445

446 
1

ROC curve for the multivariate logistic regression model.

AUC, area under the ROC curve; $\mathrm{Cl}$, confidence interval.

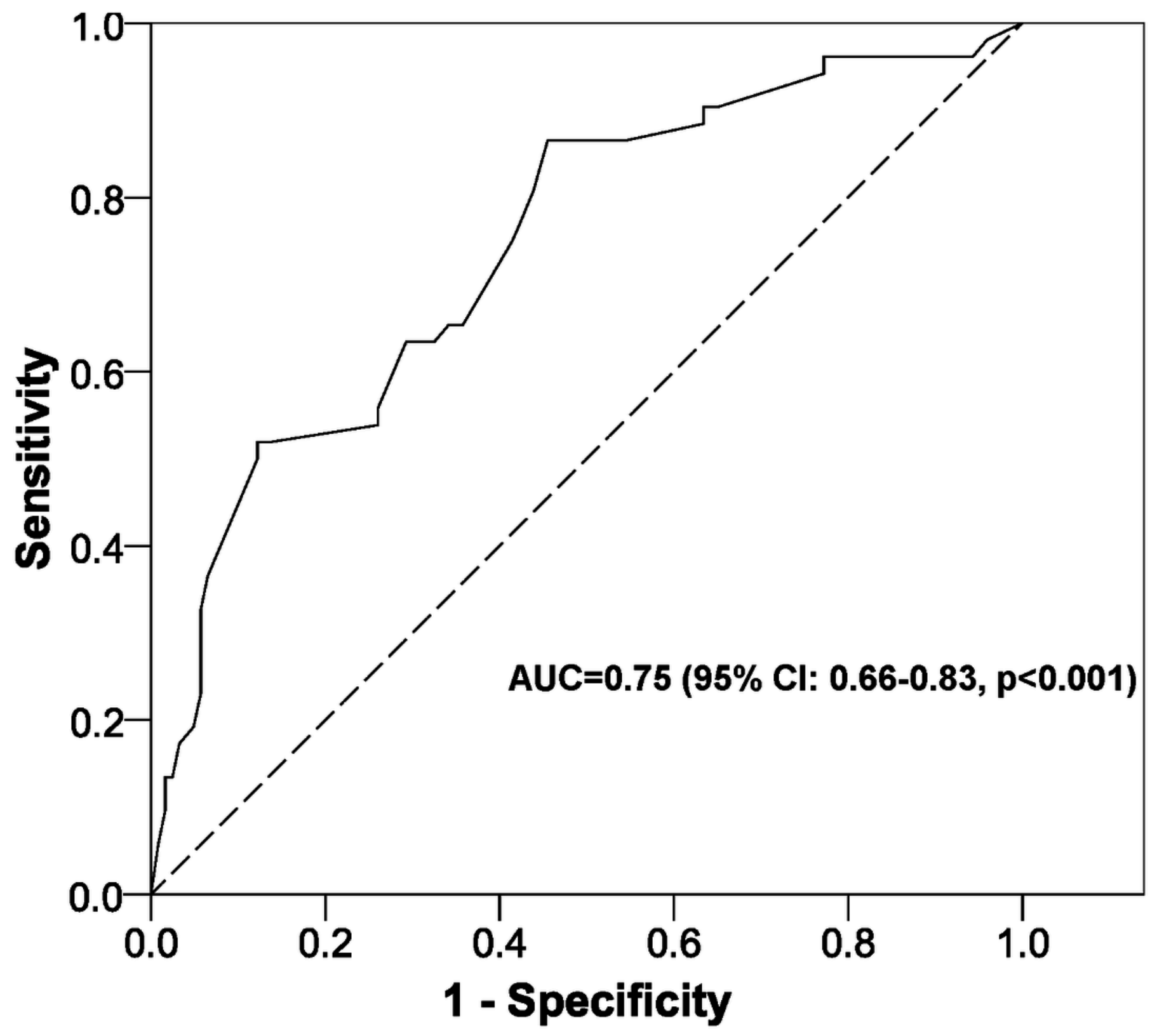


2

Predicted probabilities of STI risk in relation to Methods of Orgasm category in female university students from Alicante (Spain). 2005-2009 data.

STI: Sexually transmitted infections; $\mathrm{Cl}$ : Confidence interval. In the questionnaire the possible answers for this item (how do you normally have orgasms?) were: during vaginal intercourse, through fantasies and daydreams, by stimulation from my partner, by self stimulation, through various of the previous methods, I don't have orgasms, by other methods. As the responses varied greatly, we formed the following groups: one method, several methods, none of the methods.

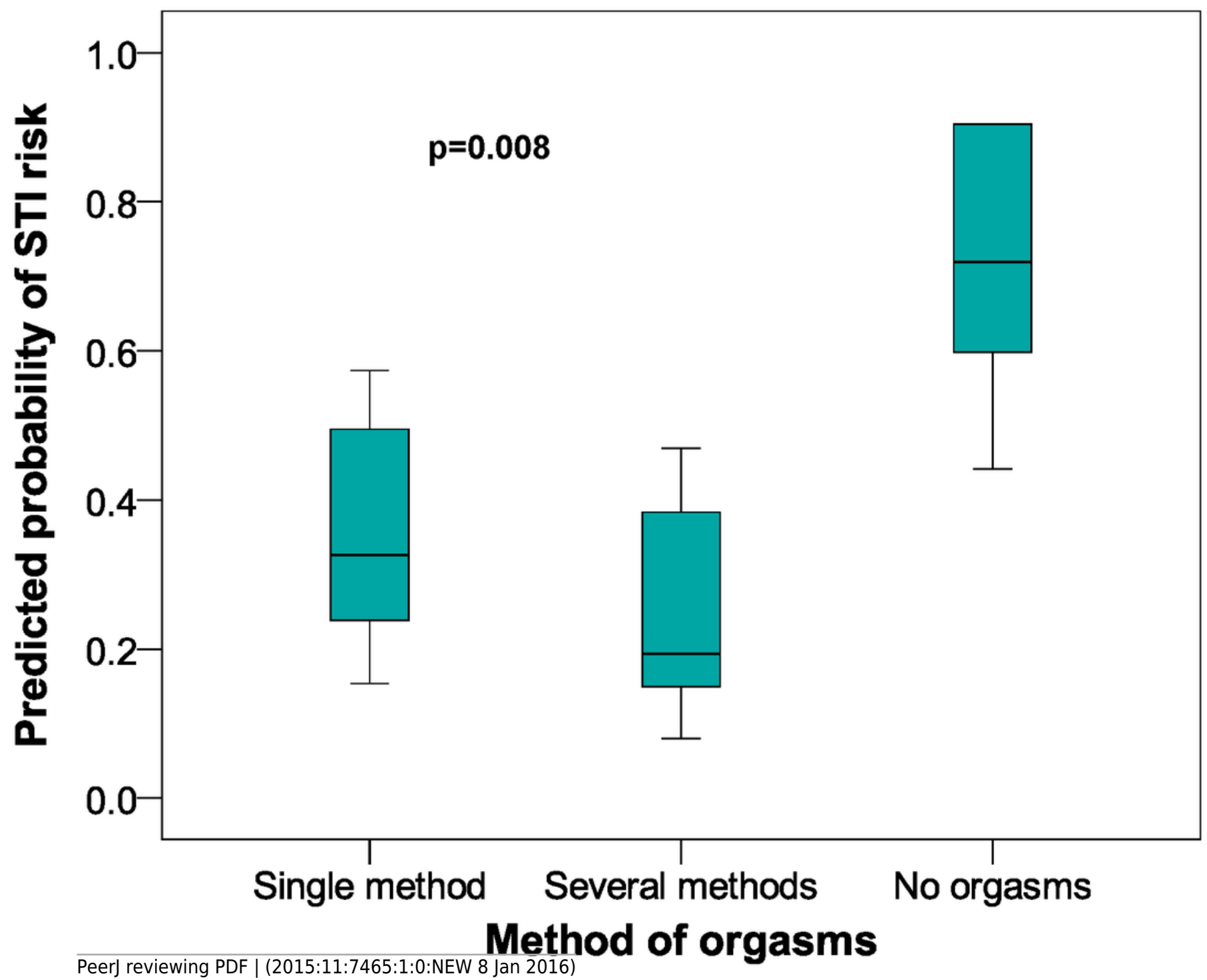


3

Predicted probabilities of STI risk in relation to Desire to increase the frequency of sexual relationships in female university students from Alicante (Spain). 2005-2009 data.

STI: Sexually transmitted infections; Cl: Confidence interval.

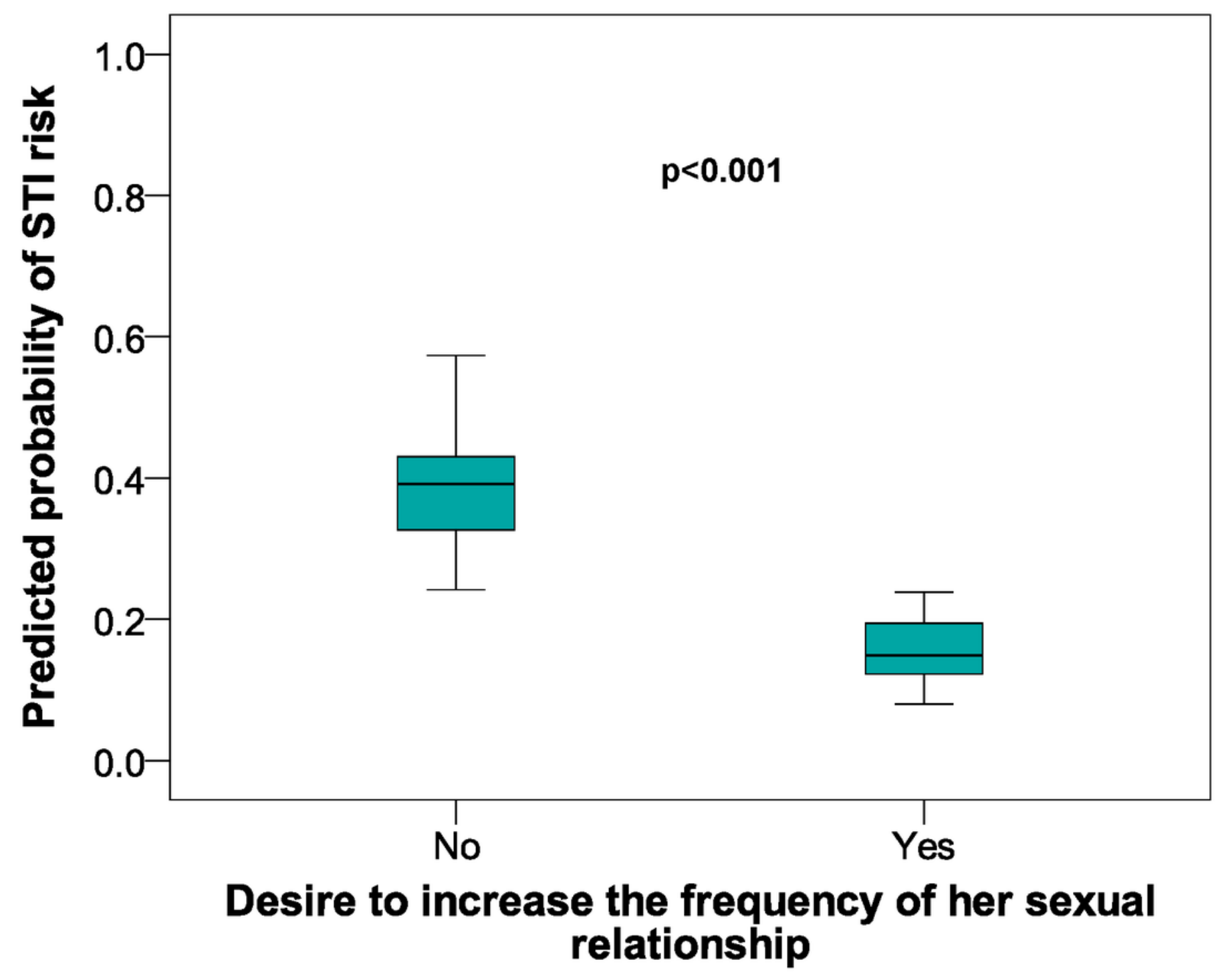




\section{Table 1 (on next page)}

Studies evaluating sexually transmitted infections risk.

*, not given; STI, sexually transmitted infections. 


\begin{tabular}{|c|c|c|c|c|}
\hline Reference & Population & $\mathrm{n}$ & $\begin{array}{l}\text { STI } \\
\text { risk } \\
(\%)\end{array}$ & Associated factors \\
\hline $\begin{array}{l}\text { Kiene, Tennen \& } \\
\text { Armeli, } 2008\end{array}$ & $\begin{array}{l}\text { Female college undergraduates who } \\
\text { consumed alcohol and sexually } \\
\text { active with casual partners }\end{array}$ & $*$ & $25-30$ & \\
\hline $\begin{array}{c}\text { Ragsdale, } \\
\text { Difranceisco \& } \\
\text { Pinkerton, } 2006\end{array}$ & $\begin{array}{l}\text { Female heterosexual tourists } \\
\text { vacationing in a resort town, aged } \\
\geq 18, \text { sexually active on vacation and } \\
\text { single (unaccompanied by a male } \\
\text { 'romantic' partner) }\end{array}$ & 60 & 69 & $\begin{array}{l}\text { No casual sex expectations, } \\
\text { no alcohol consumption, } \\
\text { being cautious regarding } \\
\text { casual sex and embarrassed } \\
\text { to discuss condoms }\end{array}$ \\
\hline $\begin{array}{l}\text { Apostolopoulos, } \\
\text { Sönmez \& Yu, } \\
2002\end{array}$ & $\begin{array}{l}\text { Female undergraduates who had a } \\
\text { sexual experience with someone they } \\
\text { just met }\end{array}$ & 321 & 34.9 & \\
\hline Finney, 2003 & $\begin{array}{l}\text { Second-year medical female students } \\
\text { on holiday }\end{array}$ & 10 & 20 & $\begin{array}{l}\text { Taking oral contraceptive } \\
\text { pill }\end{array}$ \\
\hline $\begin{array}{l}\text { de Visser et al., } \\
2003\end{array}$ & $\begin{array}{l}\text { Heterosexual women who reported } \\
\text { experience of vaginal or anal } \\
\text { intercourse in the last year with } \\
\text { casual partners }\end{array}$ & 324 & 63.8 & \\
\hline Hertliz, 2009 & $\begin{array}{l}\text { Single women without a regular } \\
\text { partner from the general population }\end{array}$ & 3,160 & 23 & \\
\hline Reece et al., 2010 & $\begin{array}{c}\text { Women aged } 18-24 \text { years old who } \\
\text { their last vaginal intercourse was } \\
\text { with casual partners }\end{array}$ & 78 & 69 & \\
\hline $\begin{array}{l}\text { Paasche-Orlow et } \\
\text { al., } 2005\end{array}$ & Incarcerated women & 423 & 61 & Low educational attainment \\
\hline $\begin{array}{l}\text { Vandepitte et al., } \\
2011\end{array}$ & $\begin{array}{l}\text { Women involved in commercial sex } \\
\text { work }\end{array}$ & 1027 & 40 & \\
\hline $\begin{array}{l}\text { Berhan \& Berhan, } \\
2012\end{array}$ & Women aged 15 - 49 years & 207,776 & 17.6 & $\begin{array}{l}\text { Living in urban areas, } \\
\text { attained secondary and } \\
\text { above education and owned } \\
\text { middle to highest wealth } \\
\text { index }\end{array}$ \\
\hline
\end{tabular}




\section{Table 2 (on next page)}

Analysis of STI risk in female university students from Alicante (Spain). 2005-2009 data.

Abbreviations: STI, Sexually transmitted infections; Adj. OR, adjusted odds ratio; $\mathrm{Cl}$, confidence interval; N/M, not in the model. *, Reference; $\dagger$, $p$-value for the complete factor. The $p$-values for the comparison with the reference are: 1) No orgasm: $0.014 ; 2)$ Several methods: 0.571 . Frequency of sexual intercourse with partner ( $6=5-7$ times/week; $5=3-4$ times/week; $4=1-2$ times/week; $3=2-3$ times/month; $2=$ once/month; $1=$ Never). Goodnessof-fit of the model: 1) likelihood ratio test: $\left.X^{2}=26.1, p<0.001 ; 2\right)$ Hosmer-Lemeshow test: $X^{2}=13.6, p=0.092$. 


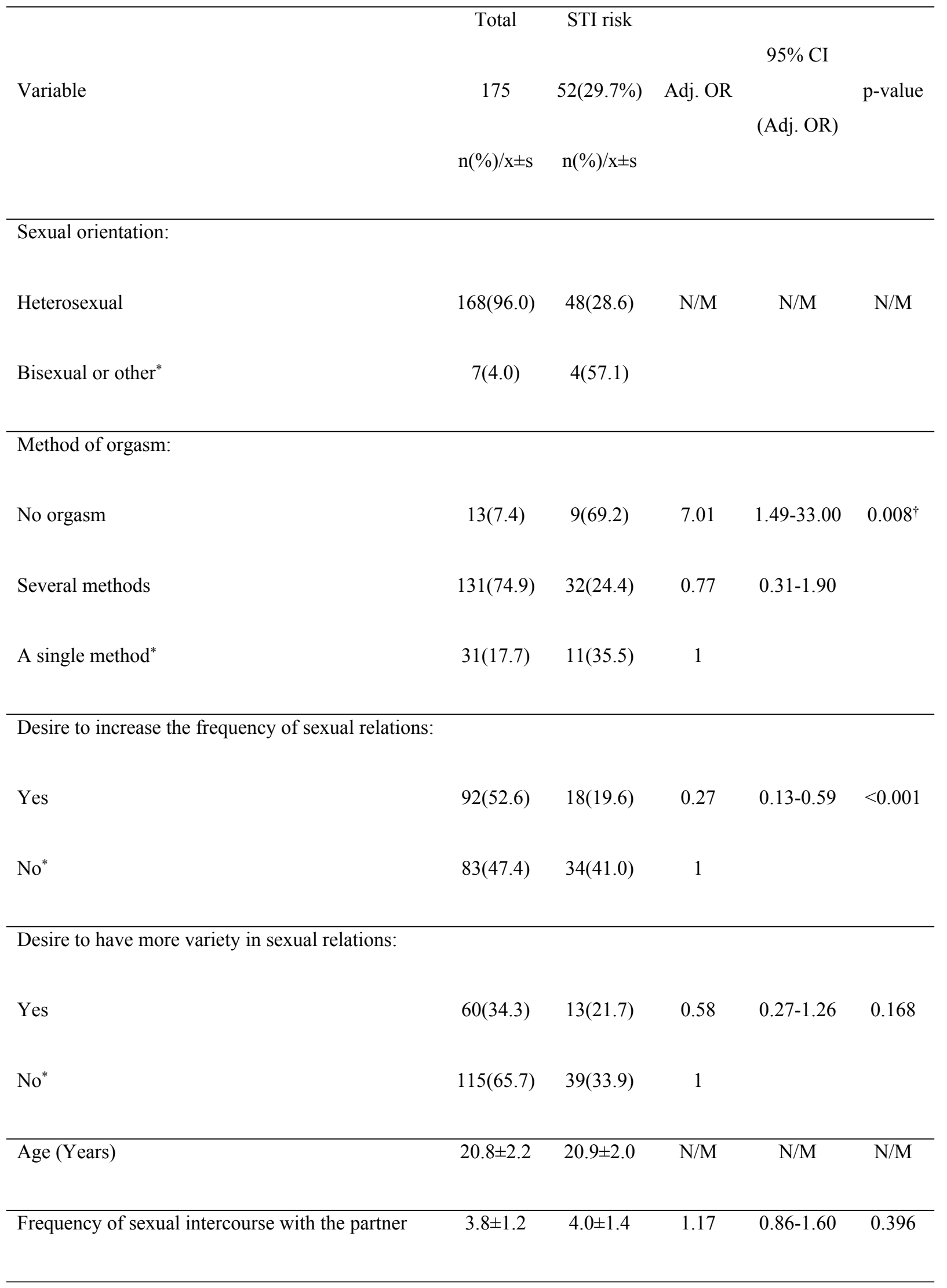


1

2

PeerJ reviewing PDF | (2015:11:7465:1:0:NEW 8 Jan 2016) 